\title{
The effect of mild dehydration on physical fitness of elderly individuals
}

\author{
Maria-Vassiliki Andrianopoulou, Nickos Geladas, Maria Koskolou* \\ From 15th International Conference on Environmental Ergonomics (ICEE XV) \\ Portsmouth, UK. 28 June - 3 July 2015
}

\section{Introduction}

The detrimental effect of dehydration on exercise performance has been studied extensively [1]. However, there is a scarce data regarding the importance of adequate hydration on the functional capacity of elderly individuals to carry out daily physical activities. In this study, the effect of mild dehydration on physical performance of elderly (60 to 75 years old) healthy subjects was evaluated.

\section{Methods}

Ten male and ten female healthy participants, 65.5(4.7) years old, performed a fitness test battery especially developed for this population, the Senior Fitness Test [2], both euhydrated (HYD) and dehydrated (by 1 to $2 \%$ of body mass) (DEH), following a random and counterbalanced order. In DEH, participants had to abstain from fluid intake for $24 \mathrm{hrs}$, while in HYD they were encouraged to consume liquids ad libitum for $24 \mathrm{hrs}$ (a minimum of 2.5 L.day $^{-1}$ was suggested) before exercise testing. Hydration level was assessed by means of urine specific gravity (USG) and urine color chart (UCC). A USG value $\geq 1020$ was defined as DEH, while USG $<1020$ as HYD. In addition to the scores achieved in the physical fitness tests, heart rate, arterial pressure, body weight and thirst sensation were recorded at rest and during recovery.

\section{Results}

A $1,4 \%$ loss of body mass ( $p<0.001)$ was achieved on average in DEH and the perception of thirst was greater $(\mathrm{p}<0.001)$. Lower scores compared with the HYD condition were observed in the tests: 6 -min walking test; 6MWT [DEH: 521.3(79.4) m vs. HYD: 565.8(94.8) m;

\footnotetext{
* Correspondence: mkoskolu@phed.uoa.gr

Department of Sports Medicine and Biology of Exercise, Faculty of Physical
} Education and Sport Science, University of Athens, Greece $\mathrm{p}<0.001$ ] and 30-sec chair sit-to-stand [DEH: 17.9(5.1) rpts vs. HYD: 19.5(4.1) rpts; $\mathrm{p}<0.05$ ]. No significant difference $(\mathrm{p}>0.05)$ was found between DEH and HYD in the tests: arm curl [DEH: 24.9(3.9) rpts vs. HYD: 26.5(5.8) rpts; $\mathrm{p}=0.101]$, back scratch [DEH: $-9.2(9,3)$ cm vs. HYD: $-8.0(9.4) \mathrm{cm} ; \mathrm{p}=0.119]$, chair sit and reach [DEH: 0.0(9.1) $\mathrm{cm}$ vs. HYD: $1(10.2) \mathrm{cm} ; \mathrm{p}=$ 0.118], 8-feet trial up and go [DEH: 5.0(1.1) sec vs. HYD: 4.9(1.1) sec; $\mathrm{p}=0.119$ ]. Males and females did not differ in performance of the fitness tests and no significant interaction was detected between gender and hydration status in any test $(\mathrm{p}>0.05)$.

\section{Discussion}

It was shown that even a mild dehydration corresponding to $1.4 \%$ of body mass was adequate to impair performance of lower extremities, as evaluated by the sit-to-stand test, and exercise tolerance, as judged by the $6 \mathrm{MWT}$, in elderly people. The distance covered in the $6 \mathrm{MWT}$ is an index of cardiopulmonary endurance and reflects the functional exercise level required for daily activities in elderly individuals, since most activities of daily living are performed at submaximal level of exertion [3].

\section{Conclusion}

The results of the present study underline the importance of adequate hydration on a daily basis for preserving functional capacity and exercise tolerance in old age.

Published: 14 September 2015

References

1. Cotter JD, Thornton SN, Lee JKW, Laursen PB: Are we being drowned in hydration advice? Thirsty for more? Extreme Physiology \& Medicine 2014, $3: 18$. 
2. Rikli RE, Jones CJ: Development and Validation of a Functional Fitness Test for Community-Residing Older Adults. Journal of Aging and Physical Activity 1999, 7:129-161.

3. ATS Statement: Guidelines for the Six-Minute Walk Test. American Journal of Respiratory and Critical Care Medicine; 2002:166:111-117.

doi:10.1186/2046-7648-4-S1-A59

Cite this article as: Andrianopoulou et al:: The effect of mild dehydration on physical fitness of elderly individuals. Extreme Physiology \& Medicine 2015 4(Suppl 1):A59.

Submit your next manuscript to BioMed Central and take full advantage of:

- Convenient online submission

- Thorough peer review

- No space constraints or color figure charges

- Immediate publication on acceptance

- Inclusion in PubMed, CAS, Scopus and Google Scholar

- Research which is freely available for redistribution

Submit your manuscript at www.biomedcentral.com/submit
C) Biomed Central 